Check for updates

Cite this: RSC Adv., 2019, 9, 6177

\title{
A hierarchical $\mathrm{Nb}_{2} \mathrm{O}_{5} @ \mathrm{NiFe}-\mathrm{MMO}$ rod array, fabricated and used as a structured photocatalyst $\uparrow$
}

\author{
Fei Liu, ${ }^{a}$ Yuwei Wang, ${ }^{a}$ Xianggui Kong, (D) *a Deqiang Lei, ${ }^{\text {b }}$ Fazhi Zhang ${ }^{\text {*a }}$ \\ and Xiaodong Lei $\mathbb{D}$ *a
}

Recently, using sunlight as a driving force with transitional metal oxides as photocatalysts, due to their unique optical and catalytic properties for organic reactions, has been considered to be a promising strategy in synthetic chemistry. Here, a hierarchically structured photocatalyst, a NiFe mixed metal oxide coated $\mathrm{Nb}_{2} \mathrm{O}_{5}$ (denoted as $\mathrm{Nb}_{2} \mathrm{O}_{5}(\mathrm{NiFe}-\mathrm{MMO}$ ) rod array has been successfully fabricated using $\mathrm{Nb}$ foil as a substrate. The $\mathrm{Nb}_{2} \mathrm{O}_{5}$ rod array was synthesized by the oxidative etching of $\mathrm{Nb}$ metal on the surface of the a substrate. The coating NiFe-MMO was obtained by the calcination of a NiFe layered double hydroxide (NiFe-LDH) precursor via the in situ epitaxial growing technique. The $\mathrm{Nb}_{2} \mathrm{O}_{5} \mathrm{aNiFe}-\mathrm{MMO}$ rod array extended the photoresponse light region from ultraviolet light around $400 \mathrm{~nm}$ to visible light around $600 \mathrm{~nm}$. With the well-designed architecture and highly dispersed $\mathrm{NiO}$ and $\mathrm{Fe}_{2} \mathrm{O}_{3}$, the as-prepared photocatalyst exhibited excellent activity and recyclability toward the reaction of aerobic coupling under relatively green conditions, with catalytic efficiency of $228 \mu \mathrm{mol} \mathrm{cm}{ }^{-2}$ (the area is that of the $\mathrm{Ni}$ foil substrate) at $30{ }^{\circ} \mathrm{C}$ for $5 \mathrm{~h}$. The present work provides a new strategy for the exploration of excellent structured photocatalysts based on transition metal oxide materials for selective aerobic oxidation of benzylamine to imine.

Received 20th December 2018
Accepted 6th February 2019

DOI: $10.1039 / c 8 r a 10432 h$

rsc.li/rsc-advances magnetically recycled and showed very good yields (88-95\%) for amine to imine. ${ }^{10}$ Many researchers have focused on developing new low energy chemical manufacturing approaches, in which photocatalytic reactions is one of the promising method.11,12 Among the most promising photocatalysts, niobium pentoxide $\left(\mathrm{Nb}_{2} \mathrm{O}_{5}\right)$ has excellent photochemical activity with the band gap of $390 \mathrm{~nm}(3.2 \mathrm{eV})$ that has been applied for the degradation of organic pollutant, ${ }^{13-15}$ water splitting to produce hydrogen ${ }^{16,17}$ and selective oxidation of benzylamine. ${ }^{9}$ However, due to the high recombination rate of photogenerated electron-hole pairs, the photocatalytic activity of $\mathrm{Nb}_{2} \mathrm{O}_{5}$ is rather limited..$^{18}$ To improve the photocatalytic activity of $\mathrm{Nb}_{2} \mathrm{O}_{5}$, several strategies have been proposed to enhance the separation of charge carriers in $\mathrm{Nb}_{2} \mathrm{O}_{5}$, such as loading metals ( $\mathrm{Pt}, \mathrm{Au}$ and $\mathrm{Cu}),{ }^{19,20}$ nonmetals $(\mathrm{N} \text { and } \mathrm{C})^{21,22}$ and metal oxides ( $\mathrm{NiO},{ }^{23} \mathrm{TiO}_{2}$ (ref. 24) and $\mathrm{Fe}_{2} \mathrm{O}_{3}$ (ref. 25)) as cocatalysts. We found especially from these reports that the photogenerated holes in semiconductor can be transferred to the NiO or $\mathrm{Fe}_{2} \mathrm{O}_{3}$ layer along the interface electric field under the light irradiation resulting a large amount of photogenerated holes are separated effectively and then prolonged the holes lifetime to participate in the photocatalytic oxidation reaction. It shows that the favorable hole-collecting process of $\mathrm{NiO}$ or $\mathrm{Fe}_{2} \mathrm{O}_{3}$ on the surface of semiconductor is the main factor being responsible for enhancing the photocatalytic efficiency.

Layered double hydroxides (LDHs) have received much attention, which are important layered anionic clays generally expressed by the formula $\left[\mathrm{M}_{1-x}{ }^{2+} \mathrm{M}_{x}{ }^{3+}(\mathrm{OH})_{2}\right]^{x+}\left(\mathrm{A}^{n-}\right)_{x / n} \cdot m \mathrm{H}_{2} \mathrm{O}$, where $\mathbf{M}^{2+}$ and $\mathbf{M}^{3+}$ are divalent and trivalent metal cations and
${ }^{a}$ State Key Laboratory of Chemical Resource Engineering, Beijing University of Chemical Technology, Beijing 100029, China. E-mail: leixd@mail.buct.edu.cn; kongxg@mail.buct.edu.cn

${ }^{b}$ Department of Neurosurgery, Union Hospital, Tongji Medical College, Huazhong University of Science and Technology, Wuhan 430022, China

$\dagger$ Electronic supplementary information (ESI) available. See DOI: 10.1039/c8ra10432h 
$\mathrm{A}^{n-}$ is the anion compensating for the positive charge of the hydroxide layers. ${ }^{26-32}$ The metal cations in LDHs are homogeneous dispersed in the layers and this merit also maintain when LDHs transform to mixed metal oxides (MMO). ${ }^{33-37}$ Among the MMOs with visible band absorbance property, NiFe-MMO has several advantages, it absorbs close to half of solar spectrum radiation, stable in most solution at $\mathrm{pH}>3$, the raw materials are abundant and inexpensive, and itself is non-toxic and environmentally benign. Recently, many researchers have discovered that the NiFe-MMO has excellent activity in photocatalysts, dye-sensitised solar cells, $\mathrm{CO}_{2}$ adsorbents and electrocatalysts for overall water splitting. ${ }^{38-40}$ While metal oxides generally suffer from poor control over particle size, morphology as well as crystalline orientation, which restricts the efficiency of charge separation and photoconversion capability. Taking into account the fact that $\mathrm{TiO}_{2}, \mathrm{Nb}_{2} \mathrm{O}_{5}$ and $\mathrm{WO}_{3}$ nanocrystal can act as a good acceptor for photogenerated electrons, the hybridization of semiconductors with NiFe-MMO would provide an effective way to enhance the charge separation and photocatalytic efficiency. ${ }^{\mathbf{4 1}-43}$

In this work, $\mathrm{Nb}_{2} \mathrm{O}_{5} @ \mathrm{NiFe}-\mathrm{MMO}$ rod array was designed and fabricated as a hierarchically structured photocatalyst, which was used to catalyze the oxidation of amines to imines. The catalytic efficiency of the hierarchical $\mathrm{Nb}_{2} \mathrm{O}_{5} @ \mathrm{NiFe}$-MMO rod array and NiFe-MMO powder was compared under the same conditions. Due to $\mathrm{NiO}$ and $\mathrm{Fe}_{2} \mathrm{O}_{3}$ homogeneous dispersed on the surface of $\mathrm{Nb}_{2} \mathrm{O}_{5}$ rod array, it was found that the catalyst has excellent photocatalytic activity and recyclability in solvent-free oxidative coupling of amines to imines.

\section{Experimental section}

\subsection{Material}

$\mathrm{Nb}$ foil (99\%) was obtained from Alfa Aesar, ammonium fluoride $\left[\mathrm{NH}_{4} \mathrm{~F}, 99.9 \%\right]$, ammonium persulphate [( $\left.\mathrm{NH}_{4}\right)_{2} \mathrm{~S}_{2} \mathrm{O}_{8}, 98.5 \%$, ammonium sulfate $\left[\left(\mathrm{NH}_{4}\right)_{2} \mathrm{SO}_{4}, 99.0 \%\right]$, nickel(II) nitrate hexahydrate $\left[\mathrm{Ni}\left(\mathrm{NO}_{3}\right)_{2} \cdot 6 \mathrm{H}_{2} \mathrm{O}, 97 \%\right]$, iron(III) nitrate nonahydrate $\left[\mathrm{Fe}\left(\mathrm{NO}_{3}\right)_{3} \cdot 9 \mathrm{H}_{2} \mathrm{O}, 98 \%\right]$, and urea $\left[\mathrm{CO}\left(\mathrm{NH}_{2}\right)_{2}\right]$ were purchased from Merck, ethanol $\left(\mathrm{C}_{2} \mathrm{H}_{5} \mathrm{OH}, 99.9 \%\right)$, acetonitrile $\left(\mathrm{CH}_{3} \mathrm{CN}\right.$, 99.9\%), and benzylamine $\left(\mathrm{C}_{7} \mathrm{H}_{9} \mathrm{~N}, 99 \%\right)$ were purchased from Energy Chemical. All chemical reagents were all used as received.

\subsection{Fabrication of $\mathrm{Nb}_{2} \mathrm{O}_{5}$ rod array}

$\mathrm{Nb}_{2} \mathrm{O}_{5}$ rod array was synthesized using a similar method with previous report. ${ }^{45}$ First, a piece of $\mathrm{Nb}$ foil $(10 \times 30 \times 0.3 \mathrm{~mm}$, 99.9\%) ultrasonic cleaned by deionized water, ethanol and acetone, respectively. $0.52 \mathrm{~g} \mathrm{NH}_{4} \mathrm{~F}(1.4 \mathrm{M})$ aqueous solution $10 \mathrm{~mL}$ and $0.57 \mathrm{~g}\left(\mathrm{NH}_{4}\right)_{2} \mathrm{~S}_{2} \mathrm{O}_{8}(0.25 \mathrm{M})$ aqueous solution $10 \mathrm{~mL}$ were mixed under magnetic stirring. Then $0.4 \mathrm{~g}\left(\mathrm{NH}_{4}\right)_{2} \mathrm{SO}_{4}$ was added into the above mixed solution and stirring for $10 \mathrm{~min}$. The solution was transferred into a $100 \mathrm{~mL}$ Teflon-lined stainless autoclave. The cleaned $\mathrm{Nb}$ foil was put into the solution followed by sealing the autoclave. After heated at $180{ }^{\circ} \mathrm{C}$ for $24 \mathrm{~h}$, the $\mathrm{Nb}$ foil was taken out, washed by the deionized water and dried in the air at $60{ }^{\circ} \mathrm{C}$ overnight. At last, the niobium pentaoxide rods on the surface of $\mathrm{Nb}$ foil substrate were obtained.

\subsection{Fabrication of $\mathrm{Nb}_{2} \mathrm{O}_{5} @ \mathrm{NiFe}-\mathrm{LDH}$ rod array}

$0.77 \mathrm{~g}$ nickel nitrate $(0.066 \mathrm{M}), 0.54 \mathrm{~g}$ ferric nitrate $(0.033 \mathrm{M})$, $1.2 \mathrm{~g}$ urea $(0.5 \mathrm{M})$, and $0.3 \mathrm{~g}$ ammonium fluoride $(0.20 \mathrm{M})$ were dissolved in $40 \mathrm{~mL}$ deionized water to obtain a mixed solution. The as-synthesised $\mathrm{Nb}_{2} \mathrm{O}_{5}$ array $(10 \times 30 \mathrm{~mm})$ was placed in the mixed solution and reacted in an autoclave at $100{ }^{\circ} \mathrm{C}$ for $10 \mathrm{~h}$, then cooled to room temperature. The resulting $\mathrm{Nb}_{2} \mathrm{O}_{5} @ \mathrm{NiFe}$ LDH rod array was washed with absolute ethanol and deionized water thoroughly and dried at $60^{\circ} \mathrm{C}$ for $5 \mathrm{~h}$.

\subsection{Fabrication of $\mathrm{Nb}_{2} \mathrm{O}_{5} @ \mathrm{NiFe}-\mathrm{MMO}$ rod array}

The prepared $\mathrm{Nb}_{2} \mathrm{O}_{5} @ \mathrm{NiFe}-\mathrm{LDH}$ rod array was placed in a muffle furnace and heated to $400{ }^{\circ} \mathrm{C}$ with a heating rate of $2{ }^{\circ} \mathrm{C} \mathrm{min}{ }^{-1}$ and kept at the temperature for $3 \mathrm{~h}$. At last, the $\mathrm{Nb}_{2} \mathrm{O}_{5} @ \mathrm{NiFe}-$ MMO rod array was obtained and used as photocatalyst for the selective aerobic oxidation of benzylamine to imine.

\subsection{Fabrication of NiFe-MMO powder}

For comparison, $0.77 \mathrm{~g}$ nickel nitrate $(0.066 \mathrm{M}), 0.54 \mathrm{~g}$ ferric nitrate $(0.033 \mathrm{M}), 1.2 \mathrm{~g}$ urea $(0.5 \mathrm{M})$, and $0.3 \mathrm{~g}$ ammonium fluoride $(0.20 \mathrm{M})$ were dissolved in $40 \mathrm{~mL}$ deionized water to obtain a mixed solution. Then the solution was transferred in an autoclave at $100{ }^{\circ} \mathrm{C}$ for $10 \mathrm{~h}$, and then cooled to room temperature. The obtained NiFe-LDH was washed with absolute ethanol and deionized water thoroughly and dried at $60{ }^{\circ} \mathrm{C}$ for $5 \mathrm{~h}$. The prepared NiFe-LDH powder was placed in a muffle furnace and heated to $400{ }^{\circ} \mathrm{C}$ with a heating rate of $2{ }^{\circ} \mathrm{C} \mathrm{min}{ }^{-1}$ and kept at the temperature for $3 \mathrm{~h}$. The NiFe-MMO powder was obtained and used as the comparison photocatalyst for the selective aerobic oxidation of benzylamine to imine.

\subsection{Material characterization}

$\mathrm{X}$-ray diffraction (XRD) patterns of the products were collected on a Rigaku XRD-6000 diffractometer using $\mathrm{Cu} \mathrm{K} \alpha$ radiation. The surface morphologies of structured photocatalyst were characterized by scanning electron microscope (SEM; Zeiss SUPRA 55) with an accelerating voltage of $20 \mathrm{kV}$, combined with energy dispersive X-ray spectroscopy (EDS). Transmission electron microscopy (TEM) images were used to characterize the microstructures of the products adopting a HITACHI HT7700 Exalens and a JEOL JEM-2010 HR-TEM. An ESCALAB 250 spectrometer (Thermo Scientific) equipped with a monochromatic $150 \mathrm{~W} \mathrm{Al} \mathrm{K \alpha}$ source was employed for X-ray photoelectron spectroscopy (XPS). The passing energy was $30 \mathrm{eV}$, and charge was compensated by low energy electrons. Binding energies are reported relative to the C 1s line at $284.8 \mathrm{eV}$. Diffuse reflectance ultraviolet and visible (DRUV-vis) spectroscopy was performed with a Tsushima UV3600 UV-vis spectrometer over the wavelength range 200 to $800 \mathrm{~nm}$. Inductively coupled plasma-mass spectrometry (ICP-MS) was adopted to analyze the chemical components of the catalysts, the solutions prepared by dissolving the samples in dilute $\mathrm{HNO}_{3}$ (1:1). ${ }^{1} \mathrm{H}$ NMR spectra were measured (CDCl3) with a Bruker AV600 spectrometer at $400 \mathrm{MHz}$. 


\subsection{Measurements of photocatalytic activity}

The catalytic reactions were performed in a double-neck quartz $(25 \mathrm{~mL})$ that was used as a photoreactor at the $\mathrm{O}_{2}$ flow rate of 10 $\mathrm{mL}$ min $^{-1}$ using a $300 \mathrm{~W}$ xenon lamp (Beijing ChangTuo Ltd.) as light source. The distance between the light source and the center of the reaction solution was approximately $10 \mathrm{~cm}$. The real light power density at the position of the reactor is determined to be $126.8 \mathrm{~mW} \mathrm{~cm}^{-2}(\lambda>300 \mathrm{~nm})$. The solution temperature was maintained at $30{ }^{\circ} \mathrm{C}$ with circulating water equipment. The initial benzylamine concentration and volume of acetonitrile (solvent) were $0.35 \mathrm{mmol}$ and $10 \mathrm{~mL}$, respectively. The structured catalyst was $1 \times 3 \mathrm{~cm}^{2}$ and the powder was $7.2 \mathrm{mg}$. The weight of powder catalyst was determined by ICP results that the loading of NiFe-MMO was approximately $2.4 \mathrm{mg}$ $\mathrm{cm}^{-2}$ on $\mathrm{Nb}$ foil. Therefore, $7.2 \mathrm{mg}$ NiFe-MMO powder ensured the same condition with $\mathrm{Nb}_{2} \mathrm{O}_{5} @ \mathrm{NiFe}-\mathrm{MMO}$ rod array. The products were determined by high quantitative analysis that were performed on a GC-MS equipment (Agilent 7890B-5977A, equipped with a DB-5MS capillary column). Before we switched on the lamp, the suspension containing one piece of catalyst was stirred for $30 \mathrm{~min}$ in the dark to attain the thermodynamic equilibrium. The reusability of the catalyst was determined using the same method repeated 5 run times. After each experimental run, the photocatalyst was washed with ethanol, and reused for the oxidation of fresh reactants.

\section{Results and discussion}

The fabrication of $\mathrm{Nb}_{2} \mathrm{O}_{5} @ \mathrm{NiFe}-\mathrm{MMO}$ rod array contains three simple steps as illustrated in Fig. 1. Firstly, $\mathrm{Nb}_{2} \mathrm{O}_{5}$ rod array was synthesized as precursor through a simple hydrothermal oxidative etching method by using $\left(\mathrm{NH}_{4}\right)_{2} \mathrm{~S}_{2} \mathrm{O}_{8}$ as oxidant. Subsequently, $\mathrm{Nb}_{2} \mathrm{O}_{5} @ \mathrm{NiFe}-\mathrm{LDH}$ rod array was fabricated by in situ hydrothermal growth of $\mathrm{NiFe}-\mathrm{LDH}$ on the surface of $\mathrm{Nb}_{2} \mathrm{O}_{5}$ rods. At last, $\mathrm{Nb}_{2}$ $\mathrm{O}_{5} @ \mathrm{NiFe}-\mathrm{MMO}$ rod array was obtained by calcined $\mathrm{Nb}_{2} \mathrm{O}_{5} @ \mathrm{NiFe}$ $\mathrm{LDH}$ rod array. The niobium foil was etched to produce $\mathrm{Nb}_{2} \mathrm{O}_{5}$ rods. ${ }^{14} \mathrm{~F}^{-}$was normally used to attack the niobium metal or niobium oxide precursor to form the fluoride containing intermediate compounds $\left(\mathrm{NH}_{4}\right)_{2} \mathrm{NbOF}_{5}{ }^{{ }^{46,47}}$ Under hydrothermal condition, the $\left(\mathrm{NH}_{4}\right)_{2} \mathrm{NbOF}_{5}$ may transfer to more stable $\mathrm{NH}_{4}$ $\mathrm{NbOF}_{4}$ by releasing one $\mathrm{NH}_{4} \mathrm{~F}$ molecule. The addition of $\left(\mathrm{NH}_{4}\right)_{2} \mathrm{SO}_{4}$ can adjust the $\mathrm{pH}$ value on the $\mathrm{Nb}$ metal surface and further promote crystallization on the surface of $\mathrm{Nb}$ foil. The following chemical reactions may occur in the hydrothermal process:

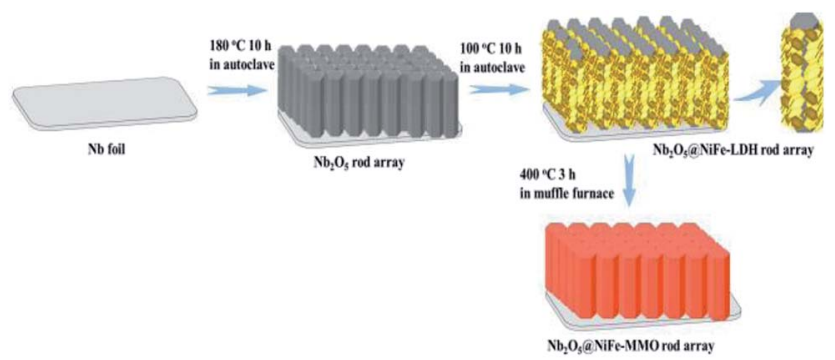

Fig. 1 Illustration of the synthesis process of $\mathrm{Nb}_{2} \mathrm{O}_{5}(\mathrm{NiFe}-\mathrm{MMO}$ rod array.
$\mathrm{Nb}+5 \mathrm{NH}_{4} \mathrm{~F}+2.5\left(\mathrm{NH}_{4}\right)_{2} \mathrm{~S}_{2} \mathrm{O}_{8}+\mathrm{H}_{2} \mathrm{O} \rightarrow\left(\mathrm{NH}_{4}\right)_{2} \mathrm{NbOF}_{5}+$ $4\left(\mathrm{NH}_{4}\right)_{2} \mathrm{SO}_{4}+2 \mathrm{H}_{2} \mathrm{SO}_{4}$

$$
\begin{gathered}
\left(\mathrm{NH}_{4}\right)_{2} \mathrm{NbOF}_{5} \rightarrow \mathrm{NH}_{4} \mathrm{NbOF}_{4}+\mathrm{NH}_{4} \mathrm{~F} \\
\mathrm{NH}_{4} \mathrm{NbOF}_{4}+1.5 \mathrm{H}_{2} \mathrm{O} \rightarrow 0.5 \mathrm{Nb}_{2} \mathrm{O}_{5}+\mathrm{NH}_{4} \mathrm{~F}+3 \mathrm{HF}
\end{gathered}
$$

Fig. 2 shows the morphology and structure of the rod arrays obtained at different stages of the fabrication. After reaction in an aqueous solution containing $\left(\mathrm{NH}_{4}\right)_{2} \mathrm{~S}_{2} \mathrm{O}_{8}$ and $\mathrm{NH}_{4} \mathrm{~F}$, the dense and uniform rods perpendicular to the surface of $\mathrm{Nb}$ foil substrate was formed (Fig. $2 \mathrm{a}$ and d). It can be seen that the average diameter of the hexagonal prism $\mathrm{Nb}_{2} \mathrm{O}_{5}$ rods is about 3 $\mu \mathrm{m}$, and the length is about $15 \mu \mathrm{m}$ (Fig. 2a and d). The uniform $\mathrm{Nb}_{2} \mathrm{O}_{5}$ rods acted as backbone for the subsequent growth of NiFe-LDH sheets by hydrothermal method. As shown in Fig. $2 b$ and e, the resulting $\mathrm{Nb}_{2} \mathrm{O}_{5} @ \mathrm{NiFe}-\mathrm{LDH}$ rod array contains a regular high density of NiFe-LDH sheets, which have a thickness of $\sim 1 \mu \mathrm{m}$. It can be clearly seen that during this process the $\mathrm{Nb}_{2} \mathrm{O}_{5}$ rods were coated with NiFe-LDH sheets (Fig. 2b). After calcination, as shown in Fig. $2 \mathrm{c}$ and $\mathrm{f}$, the resulting $\mathrm{Nb}_{2} \mathrm{O}_{5}$ @$\mathrm{NiFe}-\mathrm{MMO}$ rod array was obtained with the platelet-like NiFeLDH precursor changed into particle-stacking NiFe-MMO film with the thickness of about $300 \mathrm{~nm}$ on the surface of $\mathrm{Nb}_{2} \mathrm{O}_{5}$ rods. The distribution of $\mathrm{Nb}, \mathrm{Ni}, \mathrm{Fe}$ and $\mathrm{O}$ was visualized by using the EDS mapping technique (Fig. 3a). As shown in Fig. 3a, $\mathrm{Ni}$ and Fe elements are uniformly localized around the rod, with $\mathrm{Nb}$ mainly distributed in the center of the rod. Meanwhile, the HRTEM image of the center of $\mathrm{Nb}_{2} \mathrm{O}_{5} @ \mathrm{NiFe}$ MMO rod reveals typical regular lattice fringe with a $d$ spacing of $0.385 \mathrm{~nm}$ (Fig. 3b), corresponding to the (001) plane of $\mathrm{Nb}_{2} \mathrm{O}_{5} \cdot{ }^{35}$
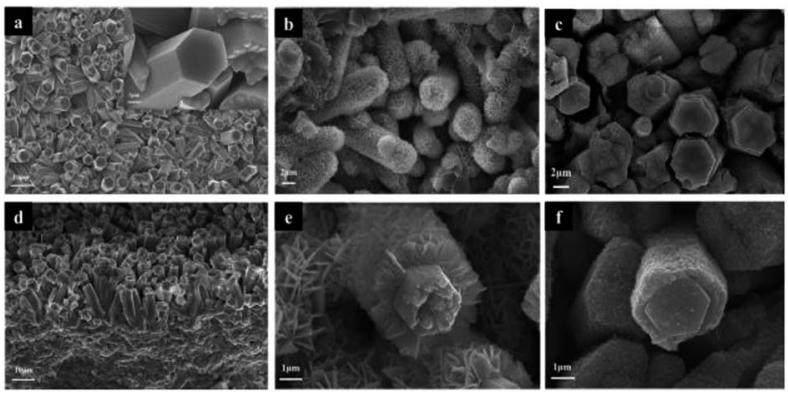

Fig. 2 SEM images of the samples: $\mathrm{Nb}_{2} \mathrm{O}_{5}$ rod array (a and d), $\mathrm{Nb}_{2} \mathrm{O}_{5} \mathrm{a}$ $\mathrm{NiFe}-\mathrm{LDH}$ rod array (b and e) amd $\mathrm{Nb}_{2} \mathrm{O}_{5} @ \mathrm{NiFe}-\mathrm{MMO}$ rod array ( $c$ and $\mathrm{f}$ ).

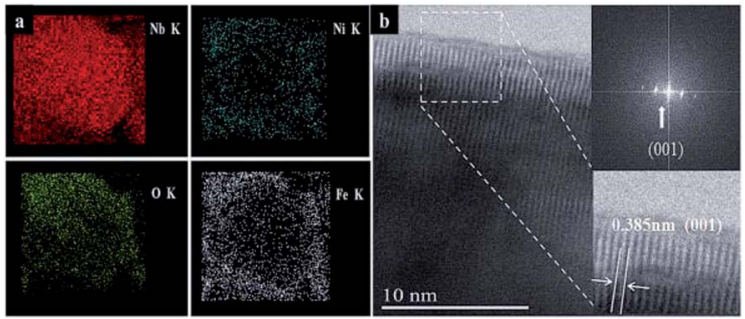

Fig. $3 \mathrm{Nb}, \mathrm{O}, \mathrm{Ni}$ and Fe elemental EDS mapping results of a $\mathrm{Nb}_{2}-$ $\mathrm{O}_{5} @ \mathrm{aNiFe}-\mathrm{MMO}$ rod (a), the HRTEM of $\mathrm{Nb}_{2} \mathrm{O}_{5}$ rod (b). 
Furthermore, the SAED pattern (inset of Fig. 3b) demonstrates the single crystalline structure of the $\mathrm{Nb}_{2} \mathrm{O}_{5}$.

From the XRD pattern, it is found that some sharp diffraction peaks superimposed on the pattern of $\mathrm{Nb}$ foil (Fig. 4). These peaks at about $22.6^{\circ}$ and $46.6^{\circ}$ that attributed to (001) and (002) planes of the hexagonal phase $\left(\mathrm{H}-\mathrm{Nb}_{2} \mathrm{O}_{5}\right)$, respectively. ${ }^{45}$ Furthermore, the much stronger peak at $22.6^{\circ}$ indicates the preferential growth of (001) plane. The result is consistent with the HRTEM results, conforming the formation of $\mathrm{Nb}_{2} \mathrm{O}_{5}$ on the surface of $\mathrm{Nb}$ foil. On the surface of $\mathrm{Nb}_{2} \mathrm{O}_{5} @ \mathrm{NiFe}-\mathrm{LDH}$ rod array, the diffraction peaks of NiFe-LDH, (003), (006), (009), (110) and (113), all appear in the XRD pattern (Fig. 4a). The chemical composition of NiFe-LDH was determined by ICP test, the molar ratio is about $\mathrm{Ni}: \mathrm{Fe}=1.6: 1.0$, and the loading of NiFe-MMO

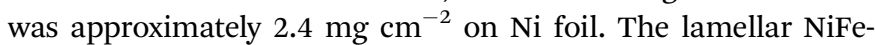
LDH was changed into particle-stacking mixed metal oxides after calcination. The XRD pattern of $\mathrm{Nb}_{2} \mathrm{O}_{5} @ \mathrm{NiFe}-\mathrm{MMO}$ rod array (Fig. 4a) confirmed the formation of a mixture of $\mathrm{NiO}$ and $\mathrm{Fe}_{2} \mathrm{O}_{3}$. The diffraction peaks of $\mathrm{NiO}$ appear at about $37^{\circ}, 43^{\circ}, 63^{\circ}$, that are attributed to (111), (200) and (220), respectively (JCPDS: 01-1239). The peaks at $14^{\circ}, 35^{\circ}, 41^{\circ}$ are (004), (110) and (200) reflections of $\mathrm{Fe}_{2} \mathrm{O}_{3}$, respectively (JCPDS: 02-1165, see in Fig. 4b).

To investigate the chemical structure of the $\mathrm{Nb}_{2} \mathrm{O}_{5} @ \mathrm{NiFe}$ MMO rod array in detail, XPS measurements were performed. As shown in Fig. 5a, the full XPS spectrum of $\mathrm{Nb}_{2} \mathrm{O}_{5} @ \mathrm{NiFe}$ -
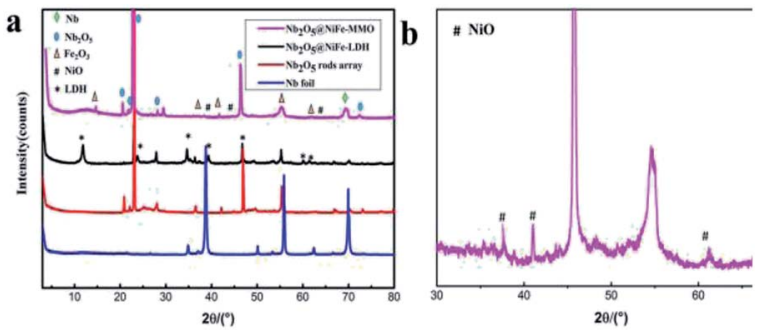

Fig. 4 The $\mathrm{XRD}$ patterns of $\mathrm{Nb}$ foil, $\mathrm{Nb}_{2} \mathrm{O}_{5}$ rod array, $\mathrm{Nb}_{2} \mathrm{O}_{5}(\mathrm{aNiFe}-$ $\mathrm{LDH}$ rod array and $\mathrm{Nb}_{2} \mathrm{O}_{5}(\mathrm{~N} \mathrm{NiFe}-\mathrm{MMO}$ rod array (a), enlarged XRD pattern of $\mathrm{Nb}_{2} \mathrm{O}_{5} \mathrm{aNiFe}-\mathrm{MMO}$ rod array (b).
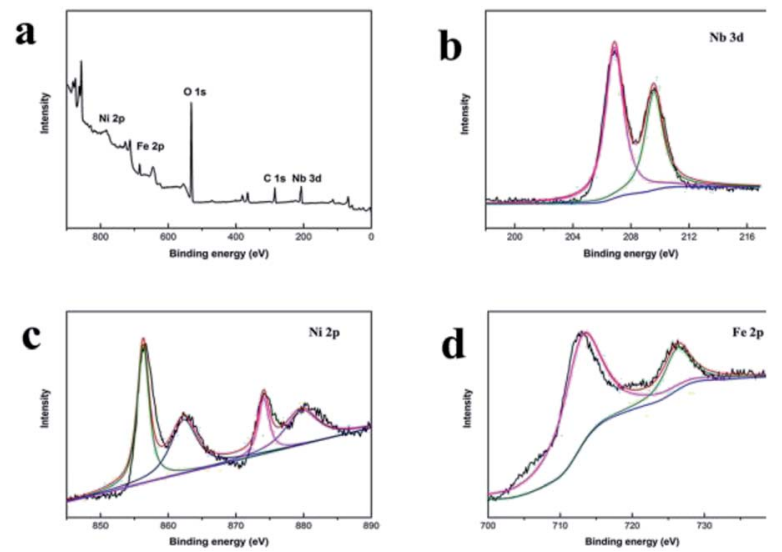

Fig. 5 The XPS full spectrum of $\mathrm{Nb}_{2} \mathrm{O}_{5}(\mathrm{NiFe}-\mathrm{MMO}$ rod array (a), XPS spectra of $\mathrm{Nb} 3 \mathrm{~d}$ (b), $\mathrm{Ni} 2 \mathrm{p}$ (c) and Fe $2 \mathrm{p}$ (d) for $\mathrm{Nb}_{2} \mathrm{O}_{5}(\mathrm{~N}$ NiFe-MMO rod array.
MMO rod array confirms the existence of $\mathrm{Nb}, \mathrm{Ni}, \mathrm{Fe}, \mathrm{O}$ and $\mathrm{C}$ (for calibration) elements in the material, in agreement with the EDS elemental mapping results. As shown in Fig. 5b, the peaks located at 207.1 and $209.9 \mathrm{eV}$, corresponding to $\mathrm{Nb} 3 \mathrm{~d}^{5 / 2}$ and $\mathrm{Nb}$ $3 \mathrm{~d}^{3 / 2}$, respectively. The bond energies of the peaks are consistent with the reported $\mathrm{Nb}_{2} \mathrm{O}_{5} \cdot{ }^{16}$ For $\mathrm{Ni}(2 \mathrm{p})$, the spectrum (Fig. 5c) is split into $\mathrm{Ni} 2 \mathrm{p}^{3 / 2}(855.4 \mathrm{eV})$ and $\mathrm{Ni} 2 \mathrm{p}^{1 / 2}(873.0 \mathrm{eV})$ peaks with the accompaniment of a doublet satellite bands, indicating that the $\mathrm{Ni}$ was mainly present in $\mathrm{Ni}^{2+}$ oxidation state $^{41}$ on the $\mathrm{Nb}_{2} \mathrm{O}_{5} @ N i F e-M M O$ rod array. The Fe 2p (Fig. 5d) core level spectra display peaks at 725.1 and $711.2 \mathrm{eV}$, which correspond to $\mathrm{Fe} 2 \mathrm{p}^{3 / 2}$ and $\mathrm{Fe} 2 \mathrm{p}^{1 / 2}$ respectively. It was difficult to distinguish the Fe phases from the XPS spectra because the various iron oxides (e.g. $\mathrm{FeO}, \mathrm{Fe}_{2} \mathrm{O}_{3}$, and $\mathrm{Fe}_{3} \mathrm{O}_{4}$ ) and oxyhydroxides (e.g. FeOOH) have similar Fe 2p core levels and peak shapes. ${ }^{41-43}$

UV-visible diffuse reflectance spectroscopy was used to investigate the bandgap energy of $\mathrm{Nb}_{2} \mathrm{O}_{5}, \mathrm{Nb}_{2} \mathrm{O}_{5} @ \mathrm{NiFe}-\mathrm{LDH}$ and $\mathrm{Nb}_{2} \mathrm{O}_{5} @ N i F e-M M O$ rod arrays, respectively (Fig. 6). The corresponding color change of the samples is displayed in the insets of Fig. 6a. Unlike the white color of $\mathrm{Nb}_{2} \mathrm{O}_{5}$, the color of $\mathrm{Nb}_{2} \mathrm{O}_{5} @ \mathrm{NiFe}-\mathrm{LDH}$ and $\mathrm{Nb}_{2} \mathrm{O}_{5} @ N i F e-M M O$ gradually changed from pale-yellow to deep-yellow after calcination, which provides direct evidence that the phase changes extended the light absorption of sample into the visible light region. The Kubelka-Munk equation was used to calculate the bandgap of the as-fabricated materials (Fig. 6b). The optical absorption coefficient $(\alpha)$ is expected to vary with the photon energy $(h \nu)$ in accordance with the relationship $(\alpha h \nu)^{n}=A\left(h \nu-E_{\mathrm{g}}\right)$. Where $A$ is a constant, $E_{\mathrm{g}}$ is the band gap energy and $n$ is an exponent characteristic of the transition process. ${ }^{44}$ For a directly allowed transition, $n=2$. The band gap of $\mathrm{Nb}_{2} \mathrm{O}_{5}$ rod array is about $3.12 \mathrm{eV}$. Compared with $\mathrm{Nb}_{2} \mathrm{O}_{5}$ rod array, both the absorption of $\mathrm{Nb}_{2} \mathrm{O}_{5} @ \mathrm{NiFe}-\mathrm{LDH}$ rod array (2.15 eV) and $\mathrm{Nb}_{2} \mathrm{O}_{5} @ \mathrm{NiFe}-\mathrm{MMO}$ rod array $(2.10 \mathrm{eV})$ shows a red shift, that of $\mathrm{Nb}_{2} \mathrm{O}_{5} @ \mathrm{NiFe}$ MMO rod array is more obvious. Hence, the band gap of $\mathrm{Nb}_{2}$ $\mathrm{O}_{5} @ \mathrm{NiFe}-\mathrm{MMO}$ rod array has decreased, this can be attributed to the coated of $\mathrm{NiO}$ and $\mathrm{Fe}_{2} \mathrm{O}_{3} \cdot{ }^{43}$

To compare the catalytic property of the as-prepared $\mathrm{Nb}_{2} \mathrm{O}_{5}$, $\mathrm{Nb}_{2} \mathrm{O}_{5} @ \mathrm{NiFe}-\mathrm{LDH}$ and $\mathrm{Nb}_{2} \mathrm{O}_{5} @ \mathrm{NiFe}-\mathrm{MMO}$ rod arrays and NiFeMMO powder, the oxidation of amines to imines under light irradiation $(\lambda>300 \mathrm{~nm})$ was used as probe reaction, and the results are summarized in Table 1 . Under $30^{\circ} \mathrm{C}$, the yields of $N$ -
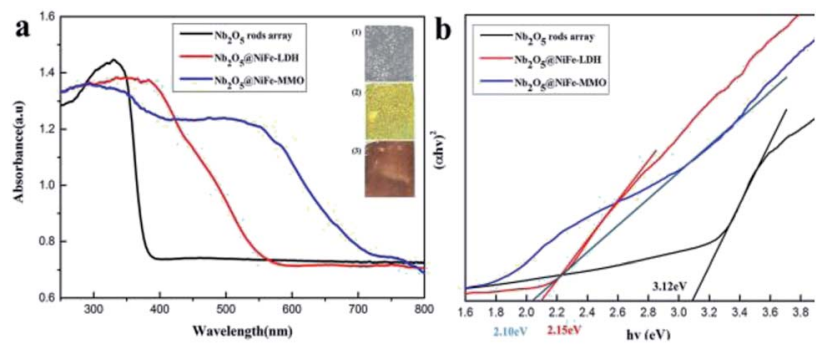

Fig. 6 (a) UV-vis diffuse reflectance spectra (insets: the optical images of samples with different colors), (b) plots of $(\alpha h \nu)^{2} v s$. the energy of absorbed light for the $\mathrm{Nb}_{2} \mathrm{O}_{5}, \mathrm{Nb}_{2} \mathrm{O}_{5} @ \mathrm{NiFe}-\mathrm{LDH}$ and $\mathrm{Nb}_{2} \mathrm{O}_{5} @ \mathrm{aNiFe}-$ MMO rod arrays. 
Table 1 Oxidative coupling of benzylamine to $N$-benzylidenebenzylamine over different catalysts. Reaction conditions: amine $(0.5$ $\mathrm{mmol})$, catalyst $\left(1 \times 3 \mathrm{~cm}^{2}\right.$ based on the $\mathrm{Nb}$ foil) or powder $(7.2 \mathrm{mg}), \mathrm{O}_{2}$ balloon (1 atm), $5 \mathrm{~h}$. (Note: for comparison, according to the amount of $\mathrm{NiFe}-\mathrm{MMO}$ powder loaded on the substrate, $2.4 \mathrm{mg}$ of NiFe-MMO powder is considered to be $1 \mathrm{~cm}^{2}$ catalyst.)

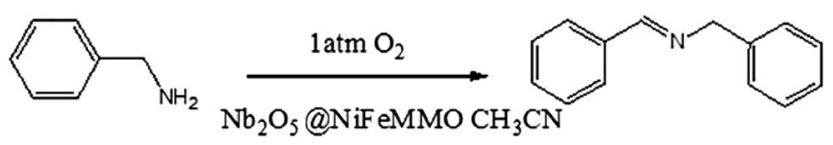

\begin{tabular}{llll}
\hline & & $\begin{array}{l}\text { Yield } \\
\left(\mu \mathrm{mol} \mathrm{cm}{ }^{-2}\right)\end{array}$ & Temperature $\left({ }^{\circ} \mathrm{C}\right)$ \\
\hline 1 & $\mathrm{Nb}_{2} \mathrm{O}_{5}$ rod array & 143 & 30 \\
2 & $\mathrm{Nb}_{2} \mathrm{O}_{5} @ N i F e-L D H$ rod array & 123 & 30 \\
3 & $\mathrm{Nb}_{2} \mathrm{O}_{5} @ N$ NFe-MMO rod array & 228 & 30 \\
4 & NiFeMMO powder & 44 & 30
\end{tabular}

benzylidene benzylamine over $\mathrm{Nb}_{2} \mathrm{O}_{5}, \mathrm{Nb}_{2} \mathrm{O}_{5} @ \mathrm{NiFe}-\mathrm{LDH}$ rod arrays and NiFe-MMO powder were 143,123 and $44 \mu \mathrm{mol} \mathrm{cm}^{-2}$, respectively. They are much lower than that over $\mathrm{Nb}_{2} \mathrm{O}_{5} @ \mathrm{NiFe}-$ MMO rod array $\left.(228 \mu \mathrm{mol} \mathrm{cm})^{-2}\right)$. It is believed the reasons are that all the samples have activity for the reaction but the photogenerated charge carriers recombined very fast on $\mathrm{Nb}_{2} \mathrm{O}_{5}$ rod array, the NiFe-LDH on $\mathrm{Nb}_{2} \mathrm{O}_{5} @ \mathrm{NiFe}-\mathrm{LDH}$ rod array exhibits poor electrical conductivity. Obviously, it illustrated that the structured $\mathrm{Nb}_{2} \mathrm{O}_{5} @ N i F e-M M O$ rod array enhanced the catalytic efficiency, which is attributed to the fact that $\mathrm{Nb}_{2} \mathrm{O}_{5}$ rod coated with $\mathrm{NiO}$ and $\mathrm{Fe}_{2} \mathrm{O}_{3}$ delays the recombination of photogenerated charge carriers.

To further understand the difference of photocatalytic activity of the $\mathrm{Nb}_{2} \mathrm{O}_{5}, \mathrm{Nb}_{2} \mathrm{O}_{5} @ \mathrm{NiFe}-\mathrm{LDH}$ and $\mathrm{Nb}_{2} \mathrm{O}_{5} @ \mathrm{NiFe}$ MMO rod arrays, the comparative time dependent study of the ability of them for oxidize benzylamine to $\mathrm{N}$-benzylidene benzylamine at $30{ }^{\circ} \mathrm{C}$ under light irradiation was provided, as shown in Fig. 7. $\mathrm{Nb}_{2} \mathrm{O}_{5} @ N i F e-M M O$ rod array exhibits a more potent photocatalytic performance than other materials, with $228 \mu \mathrm{mol} \mathrm{cm}{ }^{-2}$ of $N$-benzylidene benzylamine obtained for $5 \mathrm{~h}$ (Fig. 7). This is a large improvement of about $48 \%$ compared to

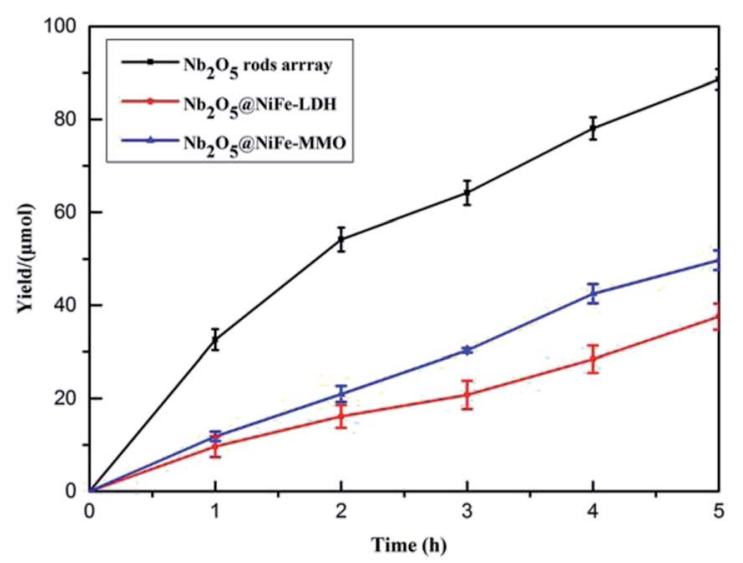

Fig. 7 The photocatalytic performance of $\mathrm{Nb}_{2} \mathrm{O}_{5}, \mathrm{Nb}_{2} \mathrm{O}_{5} @ \mathrm{NiFe}-\mathrm{LDH}$ and $\mathrm{Nb}_{2} \mathrm{O}_{5}$ aNiFe-MMO rod arrays in the oxidation of benzylamine to $\mathrm{N}$-benzylidene benzylamine.
$\mathrm{Nb}_{2} \mathrm{O}_{5}$ rod and 58\% improvement over $\mathrm{Nb}_{2} \mathrm{O}_{5} @ \mathrm{NiFe}-\mathrm{LDH}$ rod array. It is very clear that after the calcination of NiFe-LDH to obtain $\mathrm{NiO}$ and $\mathrm{Fe}_{2} \mathrm{O}_{3}$ in $\mathrm{Nb}_{2} \mathrm{O}_{5} @ \mathrm{NiFe}-\mathrm{MMO}$ rod array, the $\mathrm{N}$ benzylidene benzylamine yield was greatly improved. The GC and MS data of the reaction product are shown in the Fig. S1 and $\mathrm{S} 2, \uparrow$ respectively, confirming that the product is $\mathrm{N}$-benzylidene benzylamine and the selectivity is $100 \%$.

For investigate the stability and recyclability of $\mathrm{Nb}_{2} \mathrm{O}_{5} @ \mathrm{NiFe}$ MMO rod array, the catalyst was run up to five consecutive cycles under the same reaction condition for aerobic oxidative coupling of benzylamine. After each catalytic cycle, $\mathrm{Nb}_{2} \mathrm{O}_{5} @-$ NiFe MMO rod array was recovered by the same washing and drying procedure that provided in the section of materials and methods. Fig. 8a shows that at the first run of the catalyst, the $N$ benzylidene benzylamine yield has $228 \mu \mathrm{mol} \mathrm{cm}{ }^{-2}$. In addition, the yield for the photocatalyst diminishes very little with each cycle. However, at the fifth cycle, it still has more than $200 \mu \mathrm{mol}$ $\mathrm{cm}^{-2}$ of $N$-benzylidene benzylamine yield. By comparing the XRD pattern (Fig. 8b) and SEM images of the catalyst before and after the fifth cycle, there is no obvious change, indicating the excellent stability and recyclability of it.

It is believed that the excellent photocatalysis activity, stability and recyclability of $\mathrm{Nb}_{2} \mathrm{O}_{5} @ \mathrm{NiFe}-\mathrm{MMO}$ rod array is due to the synergistic effects between the Lewis acid sites of $\mathrm{Nb}_{2} \mathrm{O}_{5}$,
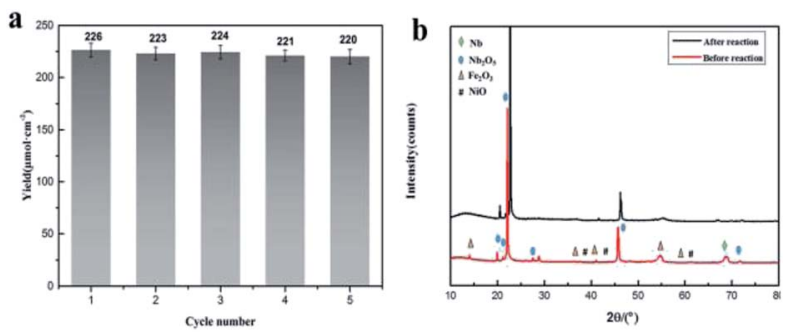

Fig. 8 Recyclability plot: the yield of imine for recycled catalyst (a) and the XRD pattern of catalyst before it used for the reaction and after $5^{\text {th }}$ run (b).

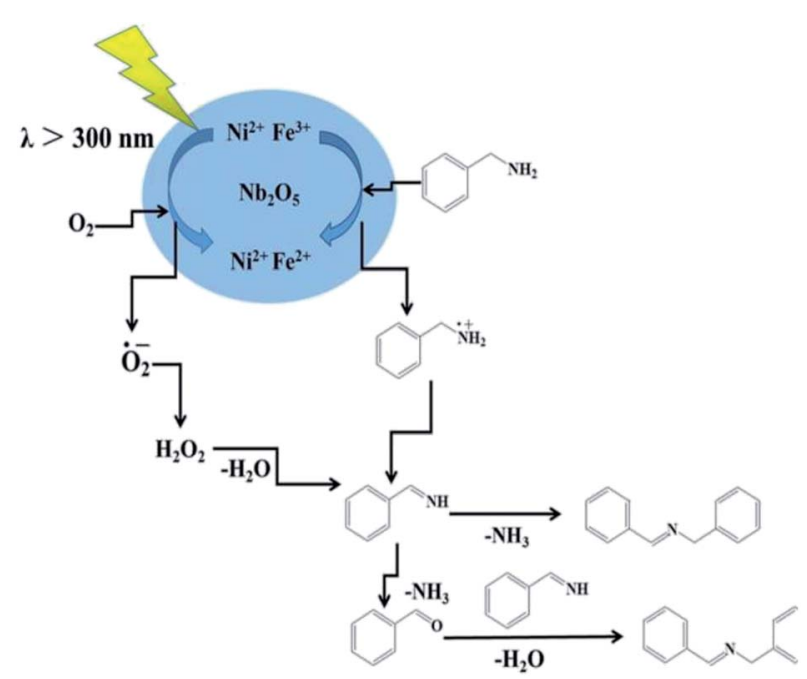

Fig. 9 The mechanism of aerobic oxidative coupling of benzylamine to imines over $\mathrm{Nb}_{2} \mathrm{O}_{5} \mathrm{QNiFe}-\mathrm{MMO}$ under visible-light irradiation. 
Table 2 The influence of substituents on the benzene ring on the reaction rate. Reaction conditions: amine $(0.5 \mathrm{mmol})$, catalyst $\left(10 \times 30 \mathrm{~mm}{ }^{2}\right.$ based on $\mathrm{Nb}$ foil substrate), $\mathrm{O}_{2}$ balloon $(1 \mathrm{~atm}), 30^{\circ} \mathrm{C}, 8 \mathrm{~h}$

Yield
$\left(\mu \mathrm{mol} \mathrm{cm}^{-2}\right)$

which are the active centers for the oxidation benzylamine under the visible light irradiation. ${ }^{48}$ And the hole-collecting effect of NiFe-MMO, which can significantly improve the separation efficiency of the photogenerated charges. The reactant were activated by both $\mathrm{Nb}_{2} \mathrm{O}_{5}, \mathrm{Fe}$ (III) and $\mathrm{Ni}$ (II) metal centers and transformed into oxygen and amine radical species which react to form $\mathrm{H}_{2} \mathrm{O}_{2}$ and benzylimine intermediates later. The in situ formed $\mathrm{H}_{2} \mathrm{O}_{2}$ may oxidize another molecule of benzylamine to imine intermediate and get converted into water which later hydrolyzes imine to aldehyde. The unstable benzylimine intermediate and aldehyde were transformed to $N$-benzylidene benzylamine, ${ }^{9,10}$ as shown in Fig. 9. The formation of free radical was also investigated by using 2,2,6,6-tetramethylpiperidine 1-oxyl (TEMPO) as free radical trap which reduces benzylamine conversion up to about $3 \%$ after its addition. The decrease of this conversion confirms the free radical mechanism for this reaction. In order to understand the substituent influence on the reaction, the catalytic oxidation was conducted on derivative compounds with electron donation groups $\left(-\mathrm{CH}_{3}\right.$ and $\left.-\mathrm{OCH}_{3}\right)$ and with the electron withdrawing group $(-\mathrm{Cl})$. The results are summarized in Table 2. The substituents on the benzene ring appear to have only a slight influence on the reaction rate and a minor influence on the selectivity. ${ }^{49-51}$ Hence all these outstanding results indicate the wide applicability of $\mathrm{Nb}_{2} \mathrm{O}_{5} @ \mathrm{NiFe}-\mathrm{MMO}$ rod array for such oxidation reactions with excellent activity and high recyclability. ${ }^{52}$ The catalytic performance for the aerobic oxidative coupling of amines over different metal oxides in some literatures is listed in Table S1. $\dagger$ $\mathrm{Nb}_{2} \mathrm{O}_{5} @ \mathrm{NiFe}-\mathrm{MMO}$ rod array has higher yields compared to some other metal oxides listed.

\section{Conclusions}

$\mathrm{Nb}_{2} \mathrm{O}_{5} @ \mathrm{NiFe}-\mathrm{MMO}$ rod array was synthesized on $\mathrm{Nb}$ foil via a facile three-step method which exhibited excellent photocatalytic activity towards self-coupling of amine to imines. The heterojunctions effectively improved the photogenerated electron and hole separation efficiency and presented a high conversion rate and selectivity for the selective oxidation of benzylamine to imine under full spectrum light irradiation and the catalytic efficiency is also increased by $48 \%$ relative to the $\mathrm{Nb}_{2} \mathrm{O}_{5}$ catalyst. Hence, $\mathrm{Nb}_{2} \mathrm{O}_{5} @ \mathrm{NiFe}-\mathrm{MMO}$ rod array is a promising photocatalyst for the aerobic oxidative coupling of amines under sunlight, especially since it maintains a high level of activity after five recycles.

\section{Conflicts of interest}

There are no conflicts to declare.

\section{Acknowledgements}

This work was supported by the National Natural Science Foundation of China (no: 2177060378 , U1707603 and 21521005) and the Program for Changjiang Scholars, Innovative Research Teams in Universities (no. IRT1205).

\section{References}

1 H. Tong, S. Ouyang, Y. Bi, N. Umezawa, M. Oshikiri and J. H. Ye, Adv. Mater., 2012, 24, 229.

2 S. Linic, P. Christopher and D. B. Ingram, Nat. Mater., 2011, 10, 911.

3 M. T. Schümperli, C. Hammond and I. Hermans, ACS Catal., 2012, 2, 1108.

4 B. Chen, L. Wang and S. Gao, ACS Catal., 2015, 5, 5851.

5 K. Yamaguchi and N. Mizuno, Angew. Chem., 2003, 42, 1479. 6 L. Aschwanden, T. Mallat, M. Maciejewski, F. Krumeich and A. Baiker, ChemCatChem, 2010, 2, 666.

7 L. Aschwanden, T. Mallat, F. Krumeich and A. Baiker, J. Mol. Catal. A: Chem., 2009, 309, 57.

8 M. H. So, Y. Liu, C. M. Ho and C. M. Che, Chem.-Asian J., 2009, 4, 1551.

9 S. Furukawa, Y. Ohno, T. Shishido, K. Teramura and T. Tanaka, ACS Catal., 2011, 1, 1150.

10 R. Dhanda and M. Kidwai, RSC Adv., 2016, 6, 53430. 
11 N. Zhang, X. Li, H. Ye, S. Chen, H. Ju, D. Liu, Y. Lin, D. Ye, et al., J. Am. Chem. Soc., 2016, 138, 8928.

12 W. Zhao, C. Liu, L. Cao, X. Yin, H. Xu and B. Zhang, RSC Adv., 2013, 3, 22944.

13 W. Dong, F. Pan, Y. Wang, S. Xiao, K. Wu, G. Q. Xu and W. Chen, Appl. Surf. Sci., 2017, 392, 514.

14 F. Huang, H. Zhao, A. Yan, Z. Li, H. Liang, Q. Gao and Y. Qiang, J. Alloys Compd., 2017, 695, 489.

15 X. Wang, G. Chen, C. Zhou, Y. Yu and G. Wang, Eur. J. Inorg. Chem., 2012, 2012, 1742.

16 W. Zhao, W. Zhao, G. Zhu, T. Lin, F. Xu and F. Huang, Dalton Trans., 2016, 45, 3888.

17 L. Li, J. Deng, R. Yu, J. Chen, Z. Wang and X. Xing, J. Mater. Chem. A, 2013, 1, 11894.

18 M. Qamar, M. Abdalwadoud, M. I. Ahmed, A. M. Azad, B. Merzougui, S. Bukola, Z. H. Yamani and M. N. Siddiqui, ACS Appl. Mater. Interfaces, 2015, 7, 17954.

19 S. Furukawa, A. Tamura, T. Shishido, K. Teramura and T. Tanaka, Appl. Catal., B, 2011, 110, 216.

20 Z. Tian, Q. Li, J. Hou, Y. Li and S. Ai, Catal. Sci. Technol., 2016, 6, 703.

21 J. Xue, R. Wang, Z. Zhang and S. Qiu, Dalton Trans., 2016, 45, 16519.

22 H. Huang, C. Wang, J. Huang, X. Wang, Y. Du and P. Yang, Nanoscale, 2014, 6, 7274.

23 L. Hou, S. Li, Y. Lin, D. Wang and T. Xie, J. Colloid Interface Sci., 2016, 464, 96.

24 S. Furukawa, T. Shishido, K. Teramura and T. Tanaka, ACS Catal., 2011, 2, 175.

25 J. Liu, S. Yang, W. Wu, Q. Tian, S. Cui, Z. Dai, F. Ren and X. Xiao, ACS Sustainable Chem. Eng., 2015, 3, 2975.

26 S. M. Xu, H. Yan and M. Wei, J. Phys. Chem., 2017, 121, 2683.

27 J. Kou, C. Lu, J. Wang, Y. Chen, Z. Xu and R. S. Varma, Chem. Rev., 2017, 117, 1445.

28 C. Wang, B. Mab, S. Xua, D. Li, S. He, Y. Zhao, J. Han, M. Wei, D. G. Evans and X. Duan, Nano Energy, 2017, 32, 463.

29 L. Yang, L. Xie, R. Ge, R. Kong, Z. Liu, Du Gu, A. M. Asiri, Y. Yao and Y. Luo, ACS Appl. Mater. Interfaces, 2017, 9, 19502.

30 L. Teruel, Y. Bouizi, P. Atienzar, V. Fornes and H. Garcia, Energy Environ. Sci., 2010, 3, 154.

31 Q. Wang, H. H. Tay, Z. Zhong, J. Luo and A. Borgna, Energy Environ. Sci., 2012, 5, 7526.
32 K. N. Dinh, P. Zheng, Z. Dai, Y. Zhang, R. Dangol, Y. Zheng, B. Li, Z. Yun and Q. Yan, Small, 2017, 1703257.

33 S. J. Kim, Y. Lee, D. Y. Lee, W. J. Lee and K. J. Kang, J. Mater. Chem. A, 2014, 2, 4136.

34 H. Zhou, Y. Song, Y. Liu, H. Li, W. Li and Z. Chang, Int. J. Hydrogen Energy, 2018, 43, 14328.

35 M. Shao, F. Ning, J. Zhao, M. Wei, D. G. Evans and X. Duan, J. Am. Chem. Soc., 2012, 134, 1071.

36 H. Qi, J. Wolfe, D. Fichou and Z. Chen, Sci. Rep., 2016, 6, 30882.

37 S. Nayak, L. Mohapatra and K. Parida, J. Mater. Chem. A, 2015, 3, 18622.

38 K. A. Shwarsctein, Y. Hu, G. D. Stucky and E. W. McFarland, Electrochem. Commun., 2009, 11, 1150.

39 H. Yen, Y. Seo, R. Guillet-Nicolas, S. Kaliaguine and F. Kleitz, Chem. Commun., 2011, 47, 10473.

40 F. Rao, Y. Zhang, Z. Wang, Q. Yu and Y. Yang, Mater. Lett., 2018, 211, 168.

41 A. Kumar and S. Bhattacharyya, ACS Appl. Mater. Interfaces, 2017, 9, 41906.

42 M. W. Louie and A. T. Bell, J. Am. Chem. Soc., 2013, 135, 12329.

43 E. Nurlaela, T. Shinagawa, M. Qureshi, D. S. Dhawale and K. Takanabe, ACS Catal., 2016, 6, 1713.

44 S. A. Ansari, M. M. Khan, S. Kalathil, A. Nisar, J. Lee and M. H. Cho, Nanoscale, 2013, 5, 9238.

$45 \mathrm{~J} . \mathrm{Wu}$ and D. Xue, CrystEngComm, 2011, 13, 1966.

46 J. He, Y. Hu, Z. Wang, W. Lu, S. Yang, G. Wu, Y. Wang, S. Wang, H. Gu and J. Wang, J. Mater. Chem. C, 2014, 2, 8185.

47 Y. Zhao, C. Eley, J. Hu, J. S. Foord, L. Ye, H. He and S. C. Tsang, Angew. Chem., 2012, 51, 3846.

48 D. Cui, L. Wang, K. Xu, L. Ren, L. Wang, Y. Yu, Y. Du and W. Hao, J. Mater. Chem. A, 2018, 6, 2193.

49 N. Gupta, A. Fukuoka and K. Nakajima, ACS Catal., 2017, 7, 2430.

50 B. Chen, L. Wang, W. Dai, S. Shang, Y. Lv and S. Gao, ACS Catal., 2015, 5, 2788.

51 S. Biswas, B. Dutta, K. Mullick, C. H. Kuo, A. S. Poyraz and S. L. Suib, ACS Catal., 2015, 5, 4394.

52 Y. Zhang, L. Pei, Z. Zheng, Y. Yuan, T. Xie, J. Yang, S. Chen, J. Wang, E. R. Waclawik and H. Zhu, J. Mater. Chem. A, 2015, 3, 18045. 